Colanzi, I. Los lazos sexo-afectivos: modos de ejercicio de cuidado en mujeres privadas de libertad. Derecho y Ciencias Sociales. Abril 2018. № 18. (Las familias y el derecho de las familias a dos años de vigencia del Código Civil y Comercial) Pgs 121-137 ISNN 1852-2971. Instituto de Cultura Jurídica y Maestría en Sociología Jurídica. FCJ y S. UNLP

\title{
Los lazos sexo-afectivos: modos de ejercicio de cuidado en mujeres privadas de libertad
}

Emotional-sexual bondings: ways of care exercising in the case of woman deprived of their

\section{liberty}

Irma Colanzi

\section{Resumen}

El ejercicio de cuidado es un derecho que se despliega de manera específica en diferentes ámbitos. El propósito de este artículo es abordar los lazos sexo-afectivos en mujeres privadas de su libertad, en tanto un tipo de ejercicio de cuidado.

A tal fin, en el trabajo se presentan las lógicas sexo-afectivas en la situación de mujeres encarceladas en el Servicio Penitenciario Bonaerense (SPB), contemplando los aportes del giro emocional. A partir de la definición de la politicidad de las emociones, como actividad de cuidado, se analizan los vínculos entre mujeres presas, y las emociones que ellas muestran en relación con sus familias, actores involucrados en la situación de privación de libertad y entre las propias mujeres detenidas. En el artículo se analizan las emociones de las mujeres privadas de libertad y la especificidad de las mismas a partir de los modos de organización colectiva entre mujeres, tomando la noción de redes de affidamento. El artículo pretende complejizar la definición de cuidado a partir del aporte del giro emocional y contribuye al estudio de la especificidad de las mujeres en las tramas del poder punitivo.

Palabras clave: lazos sexo afectivos; cuidado; affidamento; emociones.

\begin{abstract}
The exercise of care is a right that is deployed in specific ways in different areas. The purpose of this article is to analyze the sex-affective ties in women deprived of their freedom, as a type of exercise of care. The sexaffective logics are presented in the situation of women incarcerated in the Buenos Aires Penitentiary Service (SPB), contemplating the contributions of the emotional turn. From the definition of the politicity of emotions, as a care activity, the links between women prisoners are analyzed, and the emotions they show in relation to their families, actors involved in the situation of deprivation of liberty and between their own women arrested. The article analyzes the emotions of women deprived of liberty and the specificity of them based on the modes of collective organization among women, taking the notion of affidamento networks. The article aims to make the definition of care more complex based on the contribution of the emotional turn and contributes to the study of the specificity of women in the plots of punitive power.
\end{abstract}

Key words: affectionate sex ties; care; affidamento; emotions.

\footnotetext{
- Dra. en Ciencias Sociales (FaHCE, UNLP). Especialista en Abordaje de las violencias interpersonales y de género (FCJyS. UNLP). Especialista en Educación, género y sexualidades (FaHCE. UNLP). Maestranda en Políticas Públicas y Género (FLACSO). Diplomada en Ciencias Sociales con mención en Género y Políticas Públicas (FLACSO). Diploma Regional Género y Justicia (FLACSO). Licenciada y Profesora en Psicología (UNLP). Becaria Postdoctoral CONICET
} 


\title{
Los lazos sexo-afectivos: modos de ejercicio de cuidado en mujeres privadas de libertad.
}

\author{
Irma Colanzi
}

\section{Introducción}

La dimensión del cuidado, a través de los lazos sexo-afectivos, se relaciona con los interrogantes en torno a cuáles son los vínculos que despliegan las mujeres con otras compañeras detenidas, así como también qué características y direcciones presentan los lazos sexo-afectivos en el encierro. La matriz sexo-genérica (Butler, 1997) organiza y configura las lógicas de la cárcel que nos permiten interrogarnos por el cuidado, entre las mujeres y en el ejercicio de sus sexualidades. Esto posibilitó identificar las especificidades de las prácticas y tipos de contacto entre las mujeres encarceladas.

Las preguntas que motivaron este trabajo surgieron en relación a los lazos sexoafectivos vinculados con el análisis de cómo se configuran dichos lazos entre las mujeres privadas de libertad, qué características presentan, qué tipo de organización establecen en relación con el cuidado y el autocuidado, cómo construyen sus lazos sexo-afectivos, y cómo estos subvierten o no la heteronorma.

De esta manera, en el marco de la investigación de la tesis doctoral "Hacedoras de memorias: testimonios de mujeres privadas de libertad en las tramas del poder punitivo (20122016)" "se identificaron tres tipos de lazos sexo-afectivos que despliegan las mujeres en la cárcel: en primer lugar, las sexualidades y los vínculos entre las mujeres detenidas, en segundo lugar, las redes de affidamento y, en tercer lugar, el ejercicio de las violencias en los vínculos afectivos. En el presente artículo nos limitaremos al análisis de los dos primeros.

Es por ello que, en el trabajo, luego de describir cada tipo de lazo sexo- afectivo, proponemos un recorrido por las emociones, que regulan los vínculos de las mujeres, en el adentro y el afuera del contexto de encierro punitivo. Este aspecto responde a las manifestaciones emocionales que regulan las prácticas de las mujeres presas. En tal sentido, nos preguntamos cómo impactan las emociones y de qué manera inciden en el tipo de vinculación dentro de la cárcel y afuera de esta. Las emociones que se analizan son el miedo, el dolor y la vergüenza, desde los dichos de las mujeres encarceladas, como también desde quienes están abocados al abordaje de las prácticas del encierro punitivo.

\footnotetext{
${ }^{1}$ Tesis para optar por el grado de Doctora en Ciencias Sociales. Facultad de Humanidades y Ciencias de la Educación. UNLP. Tesis que forma parte de una investigación empírica con múltiples estrategias (testimonios, entrevistas, observaciones participantes y no participantes) y el entrecruzamiento de la misma que para mayor detalle se recomienda la consulta de la misma.
} 
Colanzi, I. Los lazos sexo-afectivos: modos de ejercicio de cuidado en mujeres privadas de libertad. Derecho y Ciencias Sociales. Abril 2018. $\mathrm{N}^{\circ}$ 18. (Las familias y el derecho de las familias a dos años de vigencia del Código Civil y Comercial) Pgs 121-137 ISNN 1852-2971. Instituto de Cultura Jurídica y Maestría en Sociología Jurídica. FCJ y S. UNLP

\section{Desarrollo}

Los lazos sexo-afectivos están regulados por un régimen de género (Connell, 1987), que define los modos en que se establece el tipo de contacto entre varones y mujeres, y en la cárcel determina las prácticas sexo-afectivas que despliegan las mujeres encarceladas. Consideramos que los lazos sexo-afectivos constituyen un tipo de cuidado, en un sentido amplio, así como también un modo de relacionarse que refleja el lugar paradojal de los afectos entre las propias mujeres encarceladas.

Al igual que el orden de género, ya mencionado, la matriz sexo-genérica (Butler, 1997) que organiza las identidades de género y las sexualidades, opera regulando los lazos sexoafectivos de las personas privadas de libertad, y de manera específica en las mujeres, al delimitar condiciones singulares de intercambios entre mujeres detenidas, a partir de su identidad de género y su orientación sexual. En tal sentido, analizaremos la dinámica de los lazos sexo-afectivos y las emociones, conjugando el enfoque de género y el enfoque de derechos (Pautassi, 2007), delimitando el lugar central del género como categoría de análisis (Scott, 1992) y la perspectiva feminista (Ahmed, 2014; Peluffo, 2016) a fin de atender a la singularidad de las dinámicas sexo-afectivas y emocionales propias de las mujeres en la cárcel.

Definimos el cuidado como una práctica política (Faur, 2014) y como un derecho universal (Pautassi, 2007). Conjugar ambas concepciones permite analizar en toda su complejidad el ejercicio de cuidado en la cárcel, ya sea entre las mujeres, o en el ejercicio de cuidado de las mujeres con sus hijos/as, en el cuidado por parte de los familiares hacia las mujeres presas. El cuidado entendido en términos de los lazos sexo - afectivos redimensiona las prácticas del orden íntimo y privado, y delimita un orden micro que se tensiona con las estructuras macro del poder punitivo.

Ojeda (2011) señaló que la demostración de afectos en las cárceles de varones es diferente al tipo de comportamientos afectivos que presentan las mujeres privadas de su libertad. En lo que respecta a la sexualidad, Ojeda revisó los aportes de Ward y Kassebaum (1965), quienes analizaron la noción de homosexualidad a efectos de abordar los vínculos afectivos entre mujeres. Los autores señalaron que los vínculos sexo-afectivos entre las mujeres privadas de su libertad suponen relaciones adaptativas, dada la privación de libertad, constituyen una respuesta adaptativa predominante frente a las carencias afectivas de familiares y allegados. Es por ello que nos proponemos analizar estos lazos sexo-afectivos, considerando las escenas donde los cuerpos y las sexualidades de las mujeres presas configuran sucesos que reproducen estereotipos de género (Cook y Cusack, 2010), que conviven con modos de subversión de los cuerpos, las sexualidades y los roles de género. 
Colanzi, I. Los lazos sexo-afectivos: modos de ejercicio de cuidado en mujeres privadas de libertad. Derecho y Ciencias Sociales. Abril 2018. № 18. (Las familias y el derecho de las familias a dos años de vigencia del Código Civil y Comercial) Pgs 121-137 ISNN 1852-2971. Instituto de Cultura Jurídica y Maestría en Sociología Jurídica. FCJ y S. UNLP

\section{La subversión de las sexualidades tras las rejas}

En este apartado analizaremos el ejercicio de las sexualidades en contexto de encierro punitivo, donde aparecen prácticas que subvierten el control del cuerpo femenino en la cárcel. El cuerpo y las sexualidades de las mujeres encarceladas tienen un lugar paradojal, porque son objeto de castigo y espacio de ejercicio de violencias, y al mismo tiempo son también un arma de subversión frente al gobierno carcelario. En las entrevistas realizadas en la Unidad $\mathrm{N}^{\circ} 33$ de Los Hornos, me acerqué en varias oportunidades al horario de visita de las mujeres presas. Las visitas se llevan a cabo dos veces por semana. El horario de ingreso es desde las $11 \mathrm{hs}$. hasta las $14.30 \mathrm{hs}$., pudiendo salir exclusivamente a las $18 \mathrm{hs.} \mathrm{El} \mathrm{ingreso} \mathrm{a} \mathrm{la} \mathrm{visita} \mathrm{se} \mathrm{inicia}$ con la "requisa", en la cual, después de dejar los efectos personales de valor (llaves, celular, tarjeta sube, entre otros objetos), los/as penitenciarios/as revisan los bolsos y la comida, así como también cualquier elemento que se vaya a dejar en la unidad. La requisa también consiste en un escrutinio del cuerpo de los/as visitantes, las mujeres se levantan la ropa que cubre el torso, las penitenciaras exigen mostrar el corpiño y luego se solicita que se muestre la ropa interior bajándose el pantalón. El cierre de la requisa se produce con el sello de tinta transparente que colocan en el brazo y que a la salida es leído con un censor.

En el espacio del sum de la unidad se organizan las mesas con manteles, que han sido distribuidas con tiempo. Las mujeres esperan con la comida preparada, el mate, aguardando a sus familiares, hijos/as, padres, madres, primos/as, amigos/as, parejas. La "visita" la organizan mujeres que se ocupan de distribuir mesas y lugares asignados para cada familiar, en cada pabellón. Algunas de estas mujeres tienen características propias de lo que en la cárcel se le denomina "chongo", ropas anchas, masculinas, deportivas. La figura de la "chongo" podría pensar como una performance que reproduce los estereotipos de género que se asocian con los varones en la manera de vestir, caminar, hablar. A su vez, la "chongo" ha construido vínculos de poder que no se limitan al uso de estos aditamentos considerados propios del género masculino. Esta performance es legitimada por el resto de las compañeras, a través del respeto y de la aceptación de su rol de autoridad en cada pabellón y también en el horario de la "visita" que les confieren cierta autoridad para ocupar esos roles. Después de varias horas las mujeres hacen una fila y los varones otra, y van saliendo en dos filas de diez personas como máximo, lo que exige espera y tiempo.

Finalmente, la última revisión y la entrega de los objetos de valor, con el documento de identidad en mano. Luego de varias horas adentro, la unidad va quedando distante y se observan las caravanas de familiares que van caminando hasta la avenida 149, donde está la parada de algunas líneas de micro que van a la terminal y al centro de la ciudad de La Plata. 
Colanzi, I. Los lazos sexo-afectivos: modos de ejercicio de cuidado en mujeres privadas de libertad. Derecho y Ciencias Sociales. Abril 2018. № 18. (Las familias y el derecho de las familias a dos años de vigencia del Código Civil y Comercial) Pgs 121-137 ISNN 1852-2971. Instituto de Cultura Jurídica y Maestría en Sociología Jurídica. FCJ y S. UNLP

Una de las primeras impresiones que tuve de la visita fueron las colas que se formaban en los baños, donde se iban agrupando parejas que esperaban para tener un encuentro sexual. En varias oportunidades las entrevistadas me comentaron que en el baño tiran una colcha en el piso y mantienen relaciones sexuales. Esto podría leerse como una posible reapropiación del espacio de visita en la unidad de mujeres, que les permite el ejercicio de la sexualidad, más allá del pedido de permiso de la visita íntima.

El horario de visitas tiene además varias diferencias con el pedido de visita íntima, dado que puede elegirse una pareja más allá de que sea formalmente concubino/a o casado/a, y puede también constituir un modo de conocer a alguien, algún familiar de una compañera de pabellón. En contraposición, para la visita se exige el cumplimiento de varios requisitos, tanto vinculados con la monogamia, como también con las circunstancias en las que se efectúa el encuentro. Lorena nos comentaba:

él es muy atento, muy dulce, muy caballero, nosotros empezamos a tener contacto porque es el vice - presidente del centro de estudiantes. (...). Ahí pregunté por él. (...). Le pregunté a una chica que iba a segundo año de la carrera, y me dijo 'él es el vicepresidente del centro de estudiantes, pero tiene mujer afuera y acá a C., ninguna mujer es suficiente para él, no pierdas el tiempo'. (sobre las visitas íntimas)... como novio tenés que elegir, si o si es una, la que figura como tu pareja. $\mathrm{O}$ sea, a mí me figuraba $\mathrm{N}$, aunque no venía, para pedir una visita intercarcelaria con $\mathrm{C}$. sí o sí tenía que darle la baja a N. y luego pedir la visita con C. Eso lleva dos o tres meses". (Testimonio de L., Unidad ํ33, junio de 2016).

El ejercicio de la sexualidad durante las visitas se vincula con los desarrollos de Ferrecio (2016), quien sostiene, al analizar el uso de frazadas para cubrir los encuentros sexuales, que se puede delimitar la necesidad de privacidad en un sistema que obliga a la comunidad con otros/as detenidos/as. Asimismo, la autora refiere que este tipo de prácticas regula el control de los agentes penitenciarios, y finalmente, Ferrecio refiere a las acciones por limitar la mirada de los/as otros/as detenidos/as.

Una de las estrategias de las estrategias centrales de control en las cárceles del SPB se advierten en el control de las sexualidades, lo que constituye una lógica de desubjetivación, noción que abordaremos a partir de dos acepciones. La primera vinculada con la imposibilidad de participar con voz y opinión en los procesos vinculados con las lógicas sexoafectivas en el encierro, lo que marca una "subjetividad en menos" (Chaneton y Oberti, 2003); la segunda acepción refiere a los desarrollos del Bleichmar (2004, en D’Antonio, 2016, p. 182) quien alude al momento en que el sujeto es violentada por medio de la objetalización o el menoscabo de su ser. 
Colanzi, I. Los lazos sexo-afectivos: modos de ejercicio de cuidado en mujeres privadas de libertad. Derecho y Ciencias Sociales. Abril 2018. № 18. (Las familias y el derecho de las familias a dos años de vigencia del Código Civil y Comercial) Pgs 121-137 ISNN 1852-2971. Instituto de Cultura Jurídica y Maestría en Sociología Jurídica. FCJ y S. UNLP

En el caso de las visitas íntimas, una de las profesionales de la Unidad N33, psicóloga, me comentó de un hecho ocurrido en el marco de una de estas visitas. Durante el encuentro una mujer detenida en la Unidad N³3 denunció un hecho de violencia sexual, cuando se encontraba con un hombre que había conocido en el "chat tumbero" y a quien conoció en esta instancia en un lugar cerrado y sin custodia. Las reacciones que suscitó la denuncia de violación luego de la visita se enfocaron en la sospecha ante la mujer violentada, quien fue acusada de mentirosa por algunas de las mujeres de la unidad, de acuerdo a los dichos de la entrevistada. Algunos de los comentarios que las mujeres efectuaban, referían a que la mujer que había sido agredida mentía, porque en realidad lo que había ocurrido es que ella había engañado al varón con el que había acordado el encuentro sexual, haciéndole creer que era más atractiva de lo que en verdad era.

La condena a la mujer que había denunciado la situación de violencia sexual en una visita suscitó diferentes interrogantes, como en qué medida es un modo de gobierno del SPB fomentar que la sospecha recaiga en la víctima, o de qué manera las violencias sexuales se legitiman y amparan por un supuesto engaño de una "ficción femenina", es decir de los atributos que decía tener la mujer que fue violada, antes de la visita íntima. En la escena narrada y analizada aparece una estrategia de desubjetivación, a través del ejercicio de la sexualidad, en la cual los lazos sexo - afectivos controlados por el SPB, recrean en los partenaires sexuales el ejercicio de las violencias, y al mismo tiempo, entre las mujeres de la unidad se reproducen pautas de sanción y condena, sustentadas en la sanción moral frente al ejercicio de las sexualidades.

Si bien el análisis se restringe a una situación denunciada en una visita intercarcelaria, podría desplazarse para analizar los modos en que se gobiernan los cuerpos y las sexualidades de las mujeres privadas de libertad en las cárceles de la provincia de Buenos Aires, en las que tanto por parte de los varones que asisten a las visitas, como también desde la gestión del $\mathrm{SPB}$, se objetalizan sus cuerpos y el ejercicio de sus sexualidades. Esto es central en el gobierno de las mujeres, dado que sus cautiverios dentro y fuera de la cárcel, se organizan a partir de las lógicas de las sexualidades y el género. En tal sentido, el SPB controla minuciosamente cómo se vinculan los cuerpos, sus sexualidades y los mandatos de género.

Dicho control se advierte en diferentes prácticas, por ejemplo, el control de la vestimenta de las mujeres detenidas y de sus visitas femeninas, quienes no pueden usar musculosas o pantalones cortos. También es posible hacer referencia a prácticas que son acuerdos implícitos, como por ejemplo, la prohibición de mirar a las compañeras o partenaire sexuales, en los pabellones, en las visitas y otros momentos en que se comparten espacios fuera de la celda, este tipo de control remite a una lógica monógama que impone el SPB y que 
Colanzi, I. Los lazos sexo-afectivos: modos de ejercicio de cuidado en mujeres privadas de libertad. Derecho y Ciencias Sociales. Abril 2018. $\mathrm{N}^{\circ}$ 18. (Las familias y el derecho de las familias a dos años de vigencia del Código Civil y Comercial) Pgs 121-137 ISNN 1852-2971. Instituto de Cultura Jurídica y Maestría en Sociología Jurídica. FCJ y S. UNLP

fortalece el control de las figuras de "Chongo", quienes en muchos casos tienen que recurrir al ejercicio de la violencia para mantener su autoridad, con la connivencia del SPB.

En el caso de las sexualidades las visitas intercarcelarias son definidas a partir de un precepto de monogamia, en la medida en que sólo pueden sostenerse con una persona con quien se mantenga un tipo de vínculo sexo - afectivo legítimo y acreditable.

La monogamia es un requisito del acceso a las visitas intercarcelarias, sin embargo, también se producen encuentros entre mujeres en las unidades penitenciarias. Dichos lazos son concebidos como una homosexualidad situacional, que ha sido criticada por De Souza (2011), ya que dicha concepción reproduce modos binarios y heterosexuales. De Souza también cuestiona que sean las privaciones sexuales y el aislamiento motivo de los lazos sexo-afectivos en las parejas de mujeres dentro del penal. Tanto los lazos sexo-afectivos, como las emociones que despliegan las mujeres privadas de libertad no podrían comprenderse sólo como una práctica adaptativa, sino que exige un análisis más complejo. En cuanto a este último, es preciso considerar que relacionar las privaciones sexuales con lazos que subvierten la héteronorma abona a un discurso que fortalece el binarismo y la heterosexualidad compulsiva, y no permite pensar en nuevos marcos de inteligibilidad de los cuerpos, los afectos y las sexualidades en contexto de encierro punitivo.

\section{Las redes de affidamento en relación con los lazos sexo-afectivos}

Las redes de mujeres también se desarrollan dentro de las unidades, por ejemplo, en relación con la co-responsabilidad del cuidado de niños/as. En tal sentido, Graziano y otras autoras han señalado lo siguiente:

La solidaridad entre las mujeres de algún modo reemplaza la ayuda necesaria (familiar o no) para la crianza de los hijos fuera de la experiencia carcelaria. Esta solidaridad se pone de relieve como valor central para afrontar la crianza de sus hijos en el contexto del penal, y también para poder realizar algún tipo de actividad que apunte a mejorar su bienestar físico, psicológico y emocional. La diversidad de formas de "ayuda" que despliegan en el pabellón las mujeres encarceladas se transforma así en una de las únicas posibilidades que tienen para contrarrestar los nocivos y degradantes efectos del encarcelamiento. Una ayuda que también funciona como una suerte de sostén emocional para aquellas que no reciben ningún otro tipo de "tratamiento" que no sea el de pasar sus días en un establecimiento penitenciario (Graziano et al, 2013, p. 17).

Este tipo de solidaridad puede ser leída de dos maneras: en primer lugar, primero como actos de negociación continuos, que surgen por la ausencia estatal al no garantizar el efectivo cuidado de niños/as en contexto de encierro punitivo. En segundo lugar, también es posible pensar este tipo de articulaciones por medio del concepto de red de affidamento, concepto 
Colanzi, I. Los lazos sexo-afectivos: modos de ejercicio de cuidado en mujeres privadas de libertad. Derecho y Ciencias Sociales. Abril 2018. $\mathrm{N}^{\circ}$ 18. (Las familias y el derecho de las familias a dos años de vigencia del Código Civil y Comercial) Pgs 121-137 ISNN 1852-2971. Instituto de Cultura Jurídica y Maestría en Sociología Jurídica. FCJ y S. UNLP

proveniente del feminismo italiano que alude a la ética de cuidado entre mujeres. El affidamento sería el acto por medio del cual las mujeres podrían encontrarse en la opresión con una otra igual, y construir con ella lazos de solidaridad, amor y respeto, acto que ya en sí mismo, desestabilizaría el orden patriarcal que constituye el sustrato legitimador de la violencia de género.

El riesgo de este concepto, es el uso que el SPB puede hacer de las redes de mujeres, dado que las operaciones que desarrolla el gobierno punitivo se valen de diferentes instancias de comunicación e intercambios entre ellas, para plantear mecanismos continuos de negociación que inciden en las relaciones de las mujeres que están encarceladas, por medio de las acciones del SPB.

La noción de affidamento ofrece ventajas frente a la categoría de sororidad, dado que esta última se asocia a al concepto religioso de "sor" (hermana) y no refleja la actividad que las mujeres despliegan redes activas con el objetivo de subvertir los mecanismos punitivos del encierro. La noción de affidamento también comprende las alianzas entre pares que, al decir de Ojeda, hace más llevadero el encierro y opera en el sostén de espacios institucionales como talleres, espacios recreativos, etc. Las redes que sostienen dan cuenta de la circulación de una comunidad de cuidado, que permite sobrellevar el encierro:

las familias dejan solas a las chicas detenidas ¿no? Se hacían como muy fuertes en ese sentido, entre ellas, se acompañaban mucho. Era una cuestión muy de, no si hay que llorar, yo te banco.....se generaba una red importante entre ellas. Entre ellas.....solidaridad sí, pero como algo más, más que solidaridad, como entender ¿no? Una vez nos dijo una "Y bueno cuando yo estoy mal ellas me ayudan, y al revés" me parece que una vez también, eh...con las cartas también compartirlas o leerlas en voz alta ¿sí? Y ser parte, identificarse esa es la palabra la identificación que no se si en los hombres pasa. (Entrevista a antropólogo del Ministerio de Justicia, diciembre de 2015).

El cuidado en red se advierte en los lazos afectivos que despliegan las mujeres acompañando las prácticas de cuidado infantil, ocupando el lugar de las visitas familiares, y también garantizando las redes de affidamento entre ellas. La comunidad de affidamento que configuran las mujeres privadas de su libertad constituye una herramienta esencial para sobrellevar el encierro, y se advierte en el empleo de tiempo compartido, en socializar recursos en los espacios de preparación de la comida, en talleres en la escuela, entre otras prácticas que se desarrollan en los pabellones y en la escuela.

\section{La política de las emociones en las mujeres privadas de libertad}

Los lazos sexo-afectivos sólo nos permiten caracterizar un aspecto de las prácticas específicas de las mujeres privadas de libertad. Por esta razón, analizaremos a continuación 
Colanzi, I. Los lazos sexo-afectivos: modos de ejercicio de cuidado en mujeres privadas de libertad. Derecho y Ciencias Sociales. Abril 2018. $\mathrm{N}^{\circ}$ 18. (Las familias y el derecho de las familias a dos años de vigencia del Código Civil y Comercial) Pgs 121-137 ISNN 1852-2971. Instituto de Cultura Jurídica y Maestría en Sociología Jurídica. FCJ y S. UNLP

tres emociones que han sido definidas tanto en las memorias autobiográficas de las mujeres entrevistadas, como también desde la mirada de distintos actores que intervienen en las lógicas de encierro de las mujeres.

Siguiendo la definición ya señalada acerca de la configuración del encierro a partir de un orden de género y una matriz sexo-genérica, abordaremos entonces el orden de las emociones que configuran la intimidad de las mujeres encarceladas. Berlant y Warner (1998) han señalado cómo el orden de género opera organizando el espacio de la intimidad, dominio de las emociones que nos permiten también comprender de qué manera se observa una interfaz íntima y pública en la política cultural de las emociones.

Para indagar las emociones de las mujeres privadas de libertad, consideraremos los aportes del giro emocional ${ }^{2}$, definiendo a las emociones como productos culturales. Es preciso advertir que las emociones nos brindan información de tan solo aspectos parciales del encierro o de las prácticas de castigo a las mujeres detenidas. Señalaremos primeramente cómo definimos las emociones de acuerdo a diferentes autores del giro emocional. Luego identificaremos las emociones que refieren las mujeres detenidas, siguiendo tres definiciones y caracterizaciones del miedo, el dolor y la vergüenza, para indagar las emociones propias de las mujeres presas.

Ahmed (2014) ha referido que las teorías de la emoción se "dividen” dependiendo de la definición de las emociones como sensaciones corporales o producto de la cognición. Uno de los autores aludidos por Ahmed es James (1890), quien concibe las emociones como resultado de cambios corporales. Por ello, disocian las emociones de los procesos de pensamiento (la razón). Otros autores han relacionado el sentimiento con objetos, dificultando la definición de sensación y emoción. Estas distinciones pertenecen a diferentes enfoques como es el del feminismo, el psicoanálisis, la teoría queer, entre otros.

Ahmed (2014) ha señalado que las emociones son relacionales, y esta concepción nos permite comprender de qué manera en el contacto entre mujeres en la cárcel, se gestan y reproducen emociones específicas, desarrollándose una economía afectiva, que relacionaremos también con la economía del cuidado, tanto por las prácticas que involucra, como también por la ética que exige. Es así como Ahmed ha definido las emociones como producto de una circulación, por ejemplo, en las redes de affidamento que se plantean entre las mujeres privadas de libertad.

\footnotetext{
${ }^{2}$ En los años 70 se comenzó a desarrollar en las Ciencias Sociales una dimensión de análisis que subvirtió la concepción de los cuerpos, en tanto cuerpo-animal-carne, para dar paso al lugar del cuerpo discursivo. Esta operación no lingüística y significante de la subjetividad se denominó "giro emocional", que puede articularse con los estudios de afectividad,
} 
Colanzi, I. Los lazos sexo-afectivos: modos de ejercicio de cuidado en mujeres privadas de libertad. Derecho y Ciencias Sociales. Abril 2018. $\mathrm{N}^{\circ}$ 18. (Las familias y el derecho de las familias a dos años de vigencia del Código Civil y Comercial) Pgs 121-137 ISNN 1852-2971. Instituto de Cultura Jurídica y Maestría en Sociología Jurídica. FCJ y S. UNLP

El sentimiento de solidaridad propio de las redes de affidamento podría pensarse como una práctica cultural del encierro carcelario exclusivamente en las mujeres detenidas. En tal sentido, la emoción es un producto cultural que vincula el cuerpo individual al social: "las emociones vienen de afuera y se mueven hacia adentro" (Ahmed, 2014, p. 33). Las emociones circulan entre los cuerpos. En consonancia con lo anterior, relacionaremos la definición de las emociones con la teoría queer, a través de Butler; así como también revisaremos los desarrollos del psicoanálisis.

Desde el aporte de la teoría queer las emociones son concebidas como un mecanismo de subordinación, dado que Butler (1997) propone un enfoque sobre los mecanismos psíquicos y el poder que propicia una discusión en torno a las vías de construcción de la subjetividad y la aparición del sujeto. De igual manera, en la teoría queer las formas sociales (como la heterosexualidad, la nación, la familia) son efectos de repetición, la iterabilidad de las normas que sujetan a la cultura. Los estudios de género y los feminismos han contribuido a considerar la politicidad de las emociones, y han demostrado, siguiendo el planteo de Butler, cómo el poder moldea la superficie de los cuerpos y los mundos. Otro aporte de la teoría queer es la definición de que las emociones son performativas, aspecto que abordaremos por ejemplo en el caso del dolor de la cárcel, o la vergüenza.

El dolor es una de las emociones que registran las mujeres en las experiencias traumáticas dentro y fuera de la cárcel. Esta dimensión se vincula también con los cuerpos de las mujeres detenidas. Ahmed (2014) refiere a la dimensión colectiva del dolor, ya que sería una emoción que circula en el contexto de encierro. Dos referentes del colectivo “ATRAPAMUROS” comentaban:

E2: No sé el otro día charlábamos un poco con, con el grupo que vamos a la 33 de cómo ellas tienden a pensar mucho el cuerpo, como que leen mucho que hace una con el cuerpo y tiene que ver con las lógicas de la unidad, las lógicas de las formas de vincularse entre ellas y, y con esa necesidad que impone la cárcel de estar todo el tiempo con el cuerpo alerta, alerta al cuerpo de las demás y eso hace que tengan una lectura muy fina y muy rápida de lo que a una le pasa con el cuerpo y eso lo charlábamos porque en el taller que pasó esa situación con Gisela nosotras obviamente nos asustamos

E2: Y estar seguro y tener el documento en la mano, el momento en que te piden el celular como que todo eso es de tensión máxima, y yo siempre me voy con mucho dolor de cabeza como que son dos horas y tenés que estar totalmente presente y no se te puede pasar nada. Eso después el cuerpo te lo recontra cobra, no sé cómo que se me vienen los ruidos cuando van cerrando las puertas y cuando dimensionas que forma parte del cotidiano de las personas con lo que una construye, se vuelve terrible, a veces salís del taller y escuchas que atrás están esos ruiditos de las puertas que vos vas cruzando y se 
Colanzi, I. Los lazos sexo-afectivos: modos de ejercicio de cuidado en mujeres privadas de libertad. Derecho y Ciencias Sociales. Abril 2018. $\mathrm{N}^{\circ}$ 18. (Las familias y el derecho de las familias a dos años de vigencia del Código Civil y Comercial) Pgs 121-137 ISNN 1852-2971. Instituto de Cultura Jurídica y Maestría en Sociología Jurídica. FCJ y S. UNLP

quedan del otro lado, ese momento es fuerte. Salimos, del taller siempre se generan un montón de cosas en el cuerpo entre el alivio, siempre te vas contenta y no porque el taller pudo haber salido re lindo pero fue un taller en la cárcel como que se cruzan un montón de cosas

E: Yo puedo hablar mi experiencia del cuerpo en una cárcel de varones, digamos un poco esa ambivalencia que contaba P. si la cárcel es como haber estado corriendo una hora seguida. Sentís una fatiga, un agotamiento no necesariamente para mal sino de la intensidad que tiene el encuentro, la expectativa, el estado de alerta no en un sentido de peligro sino de constante actividad en el espacio que compartís en mi caso voy sola, esa es otra cosa que marcó un antes y un después, una cosa es ir grupalmente y otra cosa es ir sola, digamos que también siento una mayor fatiga. (Entrevista Colectivo ATRAPAMUROS, julio de 2016).

Las entrevistadas refieren al lugar del cuerpo en la cárcel, y las emociones asociadas al mismo, en una vigilia o expectativa ansiosa. La vivencia de estar alerta todo el tiempo tiene un costo determinado, propio del contacto con la cárcel "y yo siempre me voy con mucho dolor de cabeza como que son dos horas y tenés que estar totalmente presente y no se te puede pasar nada. Eso después el cuerpo te lo recontra cobra". La emoción de estar alerta se asocia al dolor físico y psíquico "a veces salís del taller y escuchas que atrás están esos ruiditos de las puertas que vos vas cruzando y se quedan del otro lado, ese momento es fuerte". La experiencia del dolor que inflige el encierro necesariamente tiene un costo físico y psíquico "el cuerpo te lo re contra cobra".

En la entrevista con referentes del colectivo "ATRAPAMUROS" aparece el dolor asociado al cuerpo. Aparece ligado a tener un dolor. Igualmente, el dolor requiere de un trabajo que involucra un proceso: "En vez de suponer que el dolor no puede representarse, pensemos cómo el trabajo del dolor y el lenguaje del dolor funcionan de manera específica" (Ahmed, 2014, p. 51).

El cuerpo es una superficie para expresar el dolor, y es preciso considerar la economía de la afectividad, ligada al dolor. Sigmund Freud (1923) en El yo y el ello, analizó la afectividad del dolor. Para Freud el yo corporal está ligado a una superficie, y por ello que el yo depende de la experiencia de sensaciones corporales como ser el dolor. Un aspecto relevante que marca Ahmed (2014), es la importancia de la sociabilidad del dolor. Asimismo, la autora refiere a la noción de fetichización de la herida (Ahmed, 2014), a fin de cuestionar la cristalización en la posición de víctima del dolor, promoviendo nuevas maneras de nombrar el dolor y subvertirlo.

Peluffo (2016) refiere también a la noción de fetichización en cuanto al dolor, y asocia esta definición con el planteo de Brown, quien refiere a los imaginarios empáticos. En las 
Colanzi, I. Los lazos sexo-afectivos: modos de ejercicio de cuidado en mujeres privadas de libertad. Derecho y Ciencias Sociales. Abril 2018. $\mathrm{N}^{\circ}$ 18. (Las familias y el derecho de las familias a dos años de vigencia del Código Civil y Comercial) Pgs 121-137 ISNN 1852-2971. Instituto de Cultura Jurídica y Maestría en Sociología Jurídica. FCJ y S. UNLP

mujeres privadas de libertad se advierte la circulación del dolor, en tanto una emoción “contagiosa". Esta característica también es propia de la circulación de las emociones entre los cuerpos, más aún en un espacio como el contexto carcelario en el que las "emociones pegajosas" y no pueden ser entendidas fuera del contexto socio-afectivo en el que aparecen.

En el caso del miedo, analizaremos los mecanismos y aspectos específicos de esta emoción. Una de las características centrales del miedo es la sobredeterminación de su objeto y el lugar que ocupa el cuerpo en el despliegue del miedo. En los testimonios de las mujeres entrevistadas, el miedo aparece entre los cuerpos del otro/a agresor/a y las mujeres. En ocasiones este miedo se advierte en las prácticas de castigo de los varones agresores, así como también en las características de prácticas que se desarrollan entre las propias mujeres en las unidades.

En el testimonio de E. aparecen diferentes emociones, especialmente la del miedo, en función de las experiencias que ella narró en su testimonio. El miedo emerge en su relato relacionado con los agresores, ex parejas y varones que van marcando las circunstancias que terminan en su encarcelamiento. E. desde pequeña vivenció situaciones amenazantes y vejatorias por parte de varones, intentos de abuso sexual, violencia física, violencia psicológica. En su arresto domiciliario el miedo es la emoción que impregna su experiencia y que provoca que vuelva a la unidad penitenciaria para evitar el ejercicio de violencia que estaba padeciendo:

Un 25 de enero, en mi cumpleaños, era a los 28 años me acuerdo, estaba en pedo, y este hombre me dio una piña, estaba pasando música, me pegó borracho, yo también le pegué y le di en la cabeza. El tipo me dijo: "vos que no querés estar conmigo, querés vivir gratis (en referencia a que él había prestado su casa para que E. pudiera permanecer allí durante su arresto domiciliario), que vienen tus amigos, que vienen tus amigas". Le dije: “discúlpame yo te pedí que me dejes hasta marzo y vos me dejaste, es más te estoy dejando una moto entendés, como forma de pago, alquiler". Y me dijo: "No, no quiero la moto yo quiero estar con vos. Me agarró mucho miedo, porque el chabón me quería pegar, salí corriendo, con la pulsera". Cuando hablé al juzgado, les comenté. Dejé todo asentado, la denuncia en 1 y 60" (Testimonio de E., septiembre de 2015).

El miedo restringe ciertos cuerpos de manera específica, como el cuerpo de las mujeres, donde esta emoción opera como un mecanismo de disciplinamiento efectivo ya sea a través de la imposición de un espacio, por ejemplo, el doméstico, como también en la imposibilidad de decir y contar estos miedos.

Los mecanismos punitivos se valen del miedo, especialmente en aquellos cuerpos que se encuentran por primera vez privados de libertad. En el testimonio de P. aparece el miedo ligado a las violencias sufridas por las otras mujeres detenidas con ella: 
Colanzi, I. Los lazos sexo-afectivos: modos de ejercicio de cuidado en mujeres privadas de libertad. Derecho y Ciencias Sociales. Abril 2018. № 18. (Las familias y el derecho de las familias a dos años de vigencia del Código Civil y Comercial) Pgs 121-137 ISNN 1852-2971. Instituto de Cultura Jurídica y Maestría en Sociología Jurídica. FCJ y S. UNLP

Cuando caí detenida estuve en la Comisaría de la Mujer y en la alcaldía de Melchor Romero durante 23 días. Primero en la Comisaría sentía miedo, de que me pase algo. Estuve al principio todo un día en la Comisaría $5^{\circ}$ y luego me llevaron a la Comisaría de la Mujer y la Familia. Me trasladaron primero al Juzgado, bien temprano, estuve ahí todo el día y luego me llevaron a la Comisaría de la Mujer. Ahí me hicieron bañar con agua fría, eran malas las mujeres que estaban ahí, tenían sus días. Me dieron un pantalón y una remera. Otras mujeres detenidas me empezaron a decir que había mentido en mi causa, que era mentira lo que había dicho, que en realidad había mandado a alguien a robar a una casa, una mina grande, que mandaba a las otras. Me empujaron y me tiraron al piso, me patearon hasta que vino otra y les dijo que ya estaba. No sé si me golpearon porque era joven o porque decían que había mentido. (testimonio de P., julio de 2016).

El miedo también emerge frente al castigo físico, como indica un psicólogo entrevistado:

yo me encontraba con que vos vas, las leyes de ejecución, desde la Constitución, las leyes de ejecución penal me encontraba con una serie de circunstancias que a la hora de observarlas en la institución, vos te encontrás con situaciones que son prefocaultianas en la institución, en cuestión de cierta necesidad de marcar a alguien, lastimarlo, que se lleve un registro físico, vos te encontrás con un montón de actores incluso en la tele, no! que se pudra en la cárcel, entonces vos. Pero ahí te encontrás con un desconocimiento en términos de derecho, listo en la tele dijo que mató entonces el acto constitutivo compensatorio tiene que ser inmediato también. Hay una cuestión indicativa también, pero de manera inmediata. Ni siquiera de manera diferida: "bueno, vamos a ver si fue así, como fue". No el sólo clamor de que existe reclama la compensación. Entonces vos ves, hay algunas cuestiones de marca que se necesitan de manera inmediata, de hecho, uno lo ve: ingresa al penal, entrevista al jefe del penal. A mí me ha pasado de observar una entrevista de admisión y ver un funcionario del servicio penitenciario punirle a un detenido, para hacerle sentir físicamente el miedo. El detenido siendo entrevistado por los profesionales del grupo de admisión y seguimiento, y el jefe del penal pararse atrás y bruñirle. (Entrevista a psicólogo de la Alcaidía de Romero, septiembre de 2013).

El miedo es una emoción que caracteriza, de acuerdo a los dichos del entrevistado, el ingreso al contexto de encierro punitivo. La inexperiencia, en las primarias, mujeres que quedan privadas de libertad por primera vez, marca un anticipo del castigo posible por parte del SPB. Una abogada de la Alcaidía de Romero nos comentaba:

Bueno, las reincidentes, es decir una chica que está mucho tiempo detenida de más no. Te soy sincera, no porque están más familiarizadas, saben lo que les espera. Pero las chicas que son primarias no. Generalmente entran llorando, y muy angustiadas, por miedo, por todo esto que te digo, por temor al desconocimiento de que es lo que va a 
Colanzi, I. Los lazos sexo-afectivos: modos de ejercicio de cuidado en mujeres privadas de libertad. Derecho y Ciencias Sociales. Abril 2018. № 18. (Las familias y el derecho de las familias a dos años de vigencia del Código Civil y Comercial) Pgs 121-137 ISNN 1852-2971. Instituto de Cultura Jurídica y Maestría en Sociología Jurídica. FCJ y S. UNLP

venir, por todas estas cuestiones que por ahí ya vienen charlando desde la comisaría con otras detenidas "ay cuando te vayas al penal, lo que es el penal". Y entran acá y no saben si es un penal, si es un qué, un miedo. Y bueno, ahí están las chicas para que, también tratamos de que sean las chicas las que tengan el primer contacto con ellas, y la primera contención porque son después las que están con ellas todo el día. Y a las chicas que están en el anexo, que hacen a toda la parte de seguridad, son las que están con las detenidas todo el día. Entonces, para mi está bueno que ellas puedan generar y puedan transmitir tranquilidad y confianza, que "si necesitas algo, me avisas". (entrevista a P.M., abogada, Alcaidía de Romero. Septiembre de 2014).

El miedo opera generando un distanciamiento de los cuerpos. De esta forma se establece lo que Ahmed (2014) denomina separatidad, entre las mujeres y las penitenciarias, pero también entre ellas mismas. El miedo constituye una anticipación tensa de un suceso amenazante, de la posibilidad en la cárcel de castigos físicos, por ejemplo. El miedo funciona, como señala Freud, en tanto un síntoma, como mecanismo de defensa del yo, que asegura la supervivencia en el contexto de encierro punitivo.

Las mujeres privadas de libertad también suelen expresar y manifestar la vergüenza que les produce la situación de encierro. La detención es vivida como un acto vergonzoso frente a sus hijos/as especialmente. Cuando se vivencia la vergüenza emerge un deseo por ocultarse, por eso algunas mujeres piden a sus familiares que no lleven a sus hijos/as a la visita. “(...) en los talleres cuando íbamos, N. (una de las chicas detenidas) dijo: 'yo no (voy) porque no tengo traje", entonces ella dijo que a las chicas les da vergüenza, se sienten incómodas...por como uno venía vestido y yo le dije que tiene que ver, si no estamos para hacer un desfile de modas. Y ella me dijo, "y vos, como te sentirías si ahora te irías a una cena del Rotary Club" Y eso es importante. Para mí es muy importante la mirada que tiene si en este caso las chicas, con respecto a los funcionarios o a terceros ¿no? Cierta vergüenza (...) que ya venía con esta máxima y bueno yo ahí entendía un poco que les podía llegar a pasar de mirarte con desconfianza" (entrevista a antropólogo del Ministerio de Justicia, diciembre de 2015).

La vergüenza refleja la manera en que se interiorizan los mecanismos del poder, que se encarnan en el cuerpo de las mujeres detenidas (Butler, 2001). La vergüenza entonces estructura al yo, se convierte en el yo. El psicólogo de la Alcaidía de Romero, nos comentó lo siguiente sobre la vergüenza:

A ver vos lo que observas es, quien ya ha estado detenida no tiene ningún tipo de problema que venga la visita, que venga la familia que vengan los hijos; pero quienes son detenidas por primera vez a diferencia de los hombres vos encontrás mucha vergüenza por parte de las mujeres, entonces la refieren a las comunicaciones que estén en un hospital o que están trabajando por eso están lejos, y desde ahí la cantidad de visita y 
Colanzi, I. Los lazos sexo-afectivos: modos de ejercicio de cuidado en mujeres privadas de libertad. Derecho y Ciencias Sociales. Abril 2018. $\mathrm{N}^{\circ}$ 18. (Las familias y el derecho de las familias a dos años de vigencia del Código Civil y Comercial) Pgs 121-137 ISNN 1852-2971. Instituto de Cultura Jurídica y Maestría en Sociología Jurídica. FCJ y S. UNLP

quien la visita desciende, de alguna manera la vergüenza que les produce la instancia de detención hace que se aíslen. De las mujeres primarias te diría, no de las que reinciden. (Entrevista a psicólogo, Alcaidía de Romero, septiembre de 2014).

De acuerdo a Peluffo, es posible establecer una pedagogía de las emociones, que se asocian a construcciones culturales. La autora hace referencia al planteo de Norbert Elías (2012), quien sostiene que la vergüenza y el asco son emociones fundamentales del proceso civilizatorio. De igual manera, es posible establecer que existe una feminización de este tipo de emociones. En este sentido, Peluffo analiza los textos de Larriva de Llona, Psicología de la mujer (1919), y el libro de José Rosas El libro de oro de las niñas, textos que dan cuenta de la feminización de las emociones débiles que refuerzan las jerarquías afectivas entre los géneros.

Las mujeres privadas de libertad muestran vergüenza ante las visitas, por ejemplo, dada la sanción moral que tiene su encierro. También se observa, siguiendo los dichos del psicólogo entrevistado, que dicha vergüenza aparece especialmente en las mujeres primarias, que desconocen el contexto carcelario. Los mecanismos punitivos tienen un impacto diferencial en la política de las emociones de las mujeres privadas de libertad. Por un lado, el antropólogo entrevistado refiera a la vergüenza frente a quien viene de afuera, con otras características socio-económica.

Estas emociones se vivencian en el cuerpo, por esto podemos mencionar que el proceso en el que se advierten las emociones propias del contexto de encierro punitivo es de embodiment (Theidon, 2009) o de "experiencia corporizada". Los lazos sexo-afectivos y las emociones se vivencian en el cuerpo, por lo tanto, este es el escenario clave al momento de comprender la especificidad de los mecanismos punitivos y sus lógicas en relación con las mujeres privadas de libertad.

\section{Reflexiones finales}

A partir de los testimonios de las mujeres detenidas y los dichos de entrevistados/as de distintos espacios relacionados con la cárcel, fuimos delimitando las lógicas que imprime la matriz sexo-genérica del orden punitivo sobre las mujeres encarceladas. Se analizó el cuidado en un sentido amplio que incluye tres aspectos clave: la dimensión de la afectividad y la sexualidad, entre mujeres privadas de su libertad, así como también las redes de affidamento en relación con los lazos sexo - afectivos.

El cuidado a partir de la dimensión de los lazos sexo afectivos constituye una categoría teórica que contempla una dimensión de lo político y también responde a un plano normativo, por medio de las tecnologías legislativas de gobierno. 
Colanzi, I. Los lazos sexo-afectivos: modos de ejercicio de cuidado en mujeres privadas de libertad. Derecho y Ciencias Sociales. Abril 2018. $\mathrm{N}^{\circ}$ 18. (Las familias y el derecho de las familias a dos años de vigencia del Código Civil y Comercial) Pgs 121-137 ISNN 1852-2971. Instituto de Cultura Jurídica y Maestría en Sociología Jurídica. FCJ y S. UNLP

Las emociones son también respuestas afectivas frente al contexto carcelario, por ello se abordaron las especificidades del dolor, el miedo y la vergüenza, tres emociones presentes tanto en las voces de las mujeres, a través de sus testimonios, y en las entrevistas con actores del contexto carcelario.

El artículo contribuye entonces a analizar otros sentidos del ejercicio de cuidado, en línea con prácticas asociadas a las sexualidades, los afectos y la confianza entre mujeres privadas de libertad.

\section{Bibliografía}

Ahmed, S. (2014). La política cultural de las emociones. Ciudad de México: Universidad Nacional Autónoma de México.

Berlant, L. Warner, M. (1998). Sex in public. Intimacy. Vol. 24, N², pp.547-566.

Butler, J. (1997) Los mecanismos psíquicos del poder. Teorías sobre la sujeción. Madrid: Universidad Nacional de Valencia.

Butler, J (1997) Sujetos de sexo / género / deseo. Feminaria, 10, 1-20.Chaneton, J. Oberti, A. (2003). Historia de Ana. Revista Debate feminista, año 14, vol.27, abril de 2003, pp. 287 301.

Connell, R. (1987) Gender Regimes and the Gender Order. En Gender and Power. (pp.11914) Stanford: Stanford University Press.

Cook, R., y Cusack, S. (2009). Estereotipos de género. Perspectivas legales transnacionales. Bogotá: Profamilia.

D’Antonio, D. (2016). La prisión en los años 70. Buenos Aires: Biblos.

Faur, E. (2014). El cuidado infantil en el Siglo XXI. Mujeres malabaristas en una sociedad desigual. Buenos Aires: Siglo XXI.

Ferreccio, V. (2017). Familiares de detenidos: exploraciones en torno a prácticas de equilibrio institucional. En Anitua, Gabriel y Gual, Ramiro. (comp.). Privación de la libertad. Buenos Aires: Didot.

Freud, S. (1992). El yo y el ello. En Sigmund Freud Obras completas Tomo XIX. Amorrortu.

Gentile, F. y Tabusch, C. (2015). Emociones tras las rejas: maternidad y crianza en cárceles federales argentinas. Clínica \& Cultura IV, 59-70. Recuperado 30-3-2018 de http://www.pensamientopenal.com.ar/system/files/2015/09/doctrina42019.pdf.

Graziano, F. et al (2013). Confrontando sentidos sobre la maternidad 'no ideal': mujeres y madres presas en las cárceles de la provincia de Buenos Aires. Trabajo presentado en VII Jornadas Santiago Wallace de Investigación en Antropología Social. Sección de Antropología Social. Instituto de Ciencias Antropológicas. Facultad de Filosofía y Letras, Universidad Nacional de Buenos Aires: Buenos Aires. Resumen recuperado 30-3-2018 de https://www.aacademica.org/000-063/273.pdf

Ojeda, N. (2013). Cárcel de mujeres. Una mirada etnográfica sobre las relaciones afectivas en un establecimiento carcelario de mediana seguridad en Argentina. Revista Sociedad y Economía, 25, 237-64.

Pautassi, L. (2007). El cuidado como cuestión social desde un enfoque de derechos. Santiago de Chile: CEPAL. 
Colanzi, I. Los lazos sexo-afectivos: modos de ejercicio de cuidado en mujeres privadas de libertad. Derecho y Ciencias Sociales. Abril 2018. № 18. (Las familias y el derecho de las familias a dos años de vigencia del Código Civil y Comercial) Pgs 121-137 ISNN 1852-2971. Instituto de Cultura Jurídica y Maestría en Sociología Jurídica. FCJ y S. UNLP

Peluffo, A. (2016). En clave emocional. Cultura y afecto en América Latina. Buenos Aires: Prometeo.

Scott, J. (1992). Igualdad versus diferencia: los usos de la teoría postestructuralista. Debate Feminista, 5, 85-104.

Theidon, K. (2009). Entre prójimos. El conflicto armado interno y la política de reconciliación en el Perú. Lima: IEP. 